\title{
Low Rate Repetitive Transcranial Magnetic Stimulation (rTMS) and Gait
} Rehabilitation after Stroke

\author{
Saly H Elkholy ${ }^{*}$, Abdul Alim Atteya ${ }^{2}$, Wafaa A Hassan², Moussa Sharaf ${ }^{2}$ and Amira M El Gohary \\ ${ }^{1}$ Department of Clinical Neurophysiology, Faculty of Medicine, Cairo University, Egypt \\ ${ }^{2}$ Department of Neuromuscular Disorder and its Surgery, Faculty of Physical Therapy, Cairo University, Egypt
}

\begin{abstract}
Background: After stroke the unaffected hemisphere is dis-inhibited, due to reduction in trans-callosal inhibition from the damaged hemisphere this in turn may increase inhibition of the affected hemisphere and could impair functional recovery.
\end{abstract}

Objective: Low rate rTMS assumed to help gait rehabilitation as well as EEG synchronization after stroke. Are these two variables correlated?

Methods: Thirty stroke patients were treated by conventional physical therapy program as well as rTMS at $1 \mathrm{~Hz}$ three sessions per week. The following parameters including quantitative electroencephalogram (QEEG), timed up and go test (TUG), Fugl- Meyer scale (FMS), Cadence and gait Speed were measured before and after six weeks of the treatment program. Compared to 15 stroke patients received physiotherapy program only.

Results: All gait evaluation tests were improved after treatment in both groups, however the study group showed significant improvement than the control one. In the study group; there was significant improvement of the relative alpha band power spectrum over the treated as well as the untreated hemisphere. The relative theta/beta ratio over the central regions shows significant improvement as well. There were no significant correlations between the EEG power spectrum and the improvement of the gait evaluation tests.

Conclusion: Although rTMS for the unaffected hemisphere after stroke improves the gait ability of the patient as well as the fast frequency band of the EEG yet they are not correlated to each other.

Keywords: Stroke; Repetitive Trans-cranial Magnetic stimulation (rTMS); Timed up and go test (TUG); Fugl-Meyer scale (FMS); Cadence test; Quantitative electroencephalogram (QEEG)

\section{Introduction}

Impaired walking is one of the main functional problems that the physiotherapist encounters in caring for neurologically impaired patient. Many factors could affect the ability to walk such as range of motion (ROM), posture, bony alignment, muscle power, motor control, coordination, sensation and balance [1]. The temporal aspects of the hemiplegics gait are characterized by increased cycle time, reduced walking velocity, and reduced cadence and altered stance and swing phase periods $[2,3]$. The results of stroke vary widely depending on the size and location of the lesion.

Synaptic wisdom in neural networks with homeostatic processes appears to prevent over- and under-excitability [4]. The two cerebral hemispheres are functionally coupled and balanced as the motor cortex trans-callosal interactions are mainly inhibitory [5]. After stroke, the unaffected hemisphere is dis-inhibited. This in turn may increase inhibition of the affected hemisphere and could impair functional recovery [6].

Modulation of motor cortex activity -as the changes of cortical excitability of one hemisphere- is known to be accompanied by a modulation of excitability of homonymous regions of the contralateral hemisphere. The modulation of the corticospinal excitability caused by rTMS depends on the frequency, as high frequency rTMS is reported to increase the corticospinal excitability while low frequency rTMS lead to decrease its excitability [7-10].

Low frequency rTMS to the unaffected hemisphere showed significant decrease in simple and choice reaction time of the affected hand in stroke patients [11]. Low intensity rTMS reduces interhemispheric inhibition in both directions but is predominantly from the stimulated to the unstimulated hemisphere [12]. Spasticity could be modified by the stimulation of either the affected or the unaffected hemisphere, but the induction of movement could be achieved only by the stimulation of an intact motor pathway and its surrounding area, also the improvement in paretic extremities can be achieved with rTMS even after years of stroke when traditional rehabilitation has failed [13]. High frequency rTMS of $10 \mathrm{~Hz}$ on the affected hemisphere resulted in significant large increase in motor evoked potential amplitude and enhanced motor performance accuracy [14]. The combination between rTMS and maximal movement effort of the hemiplegic hand was noticed to improve manual performance and to reduce wrist flexor spasticity [15].

\section{Aim of Work}

Low rate rTMS assumed to help gait rehabilitation as well as EEG synchronization after stroke. Are these two variables correlated?

\section{Materials and Methods}

This is a pre-post intervention study carried on forty-five adult stroke patients of both sexes (16 males and 14 females) ranging in age from 40 to 60 years. Selection of the patients was based on careful

*Corresponding author: Saly Hassan Elkholy, Department of Clinical Neurophysiology, Faculty of Medicine, Cairo University, Egypt, E-mail: elkholysaly@kasralainy.edu.eg

Received February 14, 2014; Accepted June 29, 2014; Published July 25, 2014

Citation: Elkholy SH, Atteya AA, Hassan WA, Sharaf M, Gohary AME (2014) Low Rate Repetitive Transcranial Magnetic Stimulation (rTMS) and Gait Rehabilitation after Stroke. Int J Neurorehabilitation 1: 109. doi:10.4172/2376-0281.10001109

Copyright: () 2014 Elkholy SH, et al. This is an open-access article distributed under the terms of the Creative Commons Attribution License, which permits unrestricted use, distribution, and reproduction in any medium, provided the original author and source are credited. 
history taking and clinical examinations. The diagnosis was confirmed by CT or MRI of the brain. Stroke diagnosis was made by the treating physician according to the WHO definition of stroke "to exclude TIAs" [16].

Patients were selected to have left sided hemiplegia due to cerebrovascular accident (CVA) affecting frontal and/or parietal lobes, medically stable with mini-mental test score [17] not less than 24 , mild degree of spasticity (grade 1 to $1^{+}$according to modified Ashworth scale) [18]. Their duration of illness was not more than three months.

Patients with other neurological (Parkinsonism) or severe orthopedic disorders (unstable fractures), joints deformities or contractures, balance disturbance and recurrent stroke were excluded from the study.

Subject's eligibility to participate in the study was based on screening by the principal investigator or by the treating physical therapist at the participating location. The therapy protocol was fully clarified to the patient before his or her consent to participate in the study. This study has the approval of the ethical committee of the Faculty of Medicine, Cairo University.

Those patients were classified into two groups; study group formed of thirty patients (Group A) receiving physical therapy and rTMS and control group formed of fifteen patients (Group B) receiving physical therapy only.

The treatment policy was applied three times per week for six successive weeks (total of 18 sessions). Physical therapy program was including the following: prolonged stretch (Bobath approach) [19], strengthening exercises for the hip [20], for the back and abdominal muscles [21], balance training and gait training exercises[22]. This program took approximately one hour (not less than thirty minutes).

For group (A) immediately after physiotherapy the patient lies on a motorized bed and the cranial solenoid of the rTMS was positioned to the left hemisphere while the whole head of the patient was centered inside in the middle area (Figure 1). The intensity was set to $2 \mathrm{G}$, the frequency was $1 \mathrm{~Hz}$ for 20 minutes. The machine used was ASA Magnetic Field for rTMS. It consists of an appliance, motorized bed and solenoids. Frequency of the output impulse ranged from 0.5 to 1 $\mathrm{Hz}$, and its intensity is displayed in percentage form, from $5 \%$ to $100 \%$ of the maximum layout of the solenoid used; the maximum intensity in $G$ depending on the solenoid used "cranial solenoid maximum intensity is $80 \mathrm{G}$ [22].

The following evaluation tests were done for each patient at the entry of the study and after the end of the treatment program: Muscle tone assessment to estimate the amount of resistance that is felt according to modified Ashworth's scale. Cadence can be measured calculating the number of steps per minutes (through dividing number of steps in a designated distance on time) [23]. Timed "up and go" test (TUG) in which the patient was asked to get up from a chair, walk three meters, turn, walk back and sit down again. A stop watch was used to calculate the time of each trial and record it in seconds. The subjects received no score if they were unable to complete the test or required assistance to refrain from falling during the test [24,25]. Fugl-Meyer assessment scale (FMA) was used to measure the sensorimotor recovery after stroke [26]. Quantitative Electroencephalogram (QEEG) was used - in group A only- to measure the electrical activity of both hemispheres in the form of relative power spectrum represented by the percentage of each band's amplitude compared to the total amplitude of all frequency bands. Schwarzer Brain lab4 GmbH machine was used for recording 20 minutes of artifact free digital EEG. Full cap (19 electrodes) was applied according to the international 10/20 electrode placement system to record the following frequency bands; delta $(1-3 \mathrm{~Hz})$, theta $(4-7 \mathrm{~Hz})$, alpha $(8-12 \mathrm{~Hz})$ and beta waves $(13-16 \mathrm{~Hz}) .5$ epochs; 10 seconds each were selected for Fast Fourier Transform (FFT) analysis. The relative posterior alpha power at $\mathrm{O} 1$ and $\mathrm{O} 2$ as well as the relative theta/beta ratio at $\mathrm{C} 3$ and $\mathrm{C} 4$ were calculated before and after the treatment.

Statistical analysis: Data are summarized and analyzed using the arithmetic mean and the standard deviation. The student's t-test was used for comparison of means of two independent groups. The alpha point of 0.05 was used as a level of statistical significance. Minitb_V13 was the used statistical program.

\section{Results}

The mean value of age was $(44.06 \pm 3.71$ and $45.66 \pm 4.271$ years; $\mathrm{P}$-value $=0.2828)$, while the mean value of duration of illness was $(2.53$ \pm 0.52 and $2.533 \pm 0.516$ months; P-value $=0.999)$ for the study and the control groups; respectively.

The study group showed significant improvement in the TUG time, cadence value, speed value and FMS score in the post- treatment evaluation compared to that of the pre-treatment one.

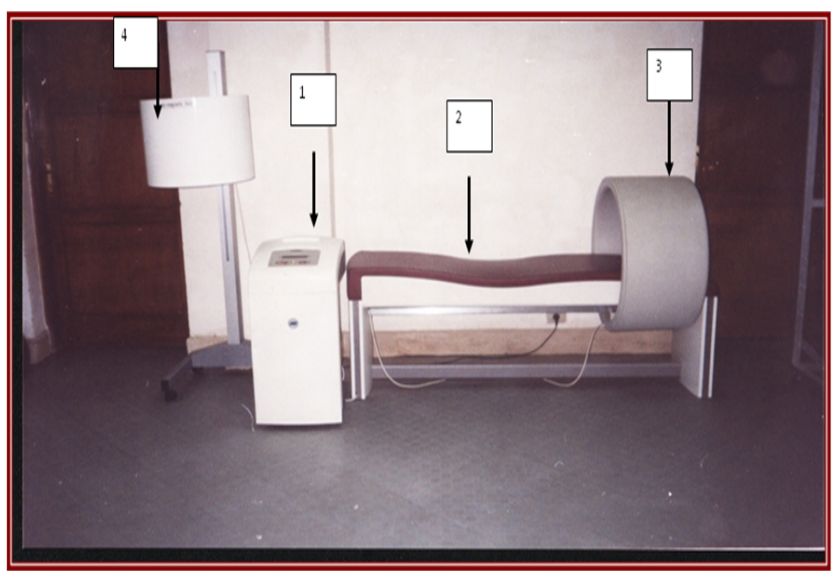

Figure 1: ASA Magnetic Field for rTMSThe appliance. 2- A motorized bed 3- Trunk solenoid. 4- Head solenoid for rTMS application. (Outpatient clinic, Faculty of Physical Therapy, Cairo University)

\begin{tabular}{|c|c|c|c|c|}
\hline $\begin{array}{c}\text { Evaluation } \\
\text { tests }\end{array}$ & pre-treatment & $\begin{array}{c}\text { post- } \\
\text { treatment } \\
\text { mean } \pm \text { SD }\end{array}$ & P-value \\
\hline TUG & Group A & $18.66 \pm 2.77$ & $14.6 \pm 2.99$ & 0.0001 \\
\hline (sec) & Group B & $18.73 \pm 1.53$ & $17.4 \pm 2.88$ & 0.031 \\
\hline & & 0.935 & 0.005 & \\
\hline Cadence & Group A & $86.4 \pm 6.3$ & $96.8 \pm 6.12$ & 0.0001 \\
\hline step/min & Group B & $86.46 \pm 4.47$ & $89.33 \pm 5.12$ & 0.024 \\
\hline & & 0.973 & 0.0011 & \\
\hline Speed Value & Group A & $0.88 \pm 0.14$ & $1.373 \pm 0.12$ & 0.0001 \\
\hline m/sec & Group B & $0.89 \pm 0.16$ & $1.06 \pm 0.25$ & 0.0046 \\
\hline & & 0.807 & 0.0002 & \\
\hline FMS score & Group A & $52.73 \pm 4.85$ & $60.93 \pm 3.92$ & 0.0001 \\
\hline & Group B & $52.8 \pm 5.86$ & $56.73 \pm 3.67$ & 0.005 \\
\hline & & 0.973 & 0.005 & \\
\hline
\end{tabular}

Table 1: The pre and post treatment values of the four evaluation tests and their statistical significance in the study (Group A) and control (Group B) patients 


\begin{tabular}{|r|r|r|r|r|r|r|r|r|r|}
\hline Group A & \multicolumn{3}{|c|}{ Relative Alpha Power } & \multicolumn{4}{|c|}{ Relative theta/beta Ratio } \\
\hline & O1b & O1a & O2b & O2a & C3b & C3a & C4b & C4a \\
\hline min & 11.96 & 21.88 & 8.25 & 8.66 & 1.04 & 0.4 & 1.54 & 0.58 \\
\hline max & 78.92 & 79.8 & 50.8 & 71.39 & 4.42 & 3.16 & 3.87 & 2.5 \\
\hline mean & 37.98 & 47.16 & 27.28 & 40.03 & 2.75 & 1.688 & 2.63 & 1.44 \\
\hline SD & 28.61 & 25.5 & 15.18 & 23.25 & 1.1 & 1.16 & 0.94 & 0.73 \\
\hline P-value & 0.03 & & 0.03 & & & 0.01 & & 0.006 \\
\hline
\end{tabular}

Table 2: Theta/ beta ratio at central areas and relative posterior alpha power of both hemispheres before (b) and after (a) rTMS and their significant correlation in the study group

\begin{tabular}{|l|l|l|l|l|}
\hline Group A & TUG & Cadence & Speed & FMS \\
\hline O1 & 0.381 & 0.303 & -0.564 & -0.282 \\
\hline O2 & 0.302 & 0.319 & 0.232 & 0.098 \\
\hline C3 & 0.407 & -0.16 & -0.054 & -0.062 \\
\hline C4 & 0.467 & -0.184 & -0.181 & -0.099 \\
\hline
\end{tabular}

Table 3: The correlation between posterior alpha rhythm at $\mathrm{O} 1$ and $\mathrm{O} 2$ as well as the theta /beta ratio at $\mathrm{C} 3$ and $\mathrm{C} 4$ and the changes in the evaluation tests of gait in the study group

The control group showed also significant improvement in the post-treatment evaluation tests in comparison to that of the pretreatment one.

When comparing the two groups together; the pre-treatment evaluation tests showed insignificant values while the post-treatment one was significant (Table 1).

The study group showed significant improvement in the theta/ beta ratio over the treated unaffected hemisphere at $\mathrm{C} 3$ as well as the untreated affected hemisphere at $\mathrm{C} 4$. The relative power spectrum of the posterior alpha rhythm at $\mathrm{O} 1$ and $\mathrm{O} 2$ also showed significant improvement in the post treatment evaluation compared to the pretreatment one (Table 2).

There were no significant correlations between the changes in the alpha power spectrum or that of the theta/beta ratio at any of the examined positions of either hemispheres and the changes of the evaluation tests (TUG, Cadence, Speed and FMS) at the post treatment evaluation (Table 3 ).

\section{Discussion}

The selection of patients in this study was aimed to exclude aphasic patients to concentrate on the effect of rTMS on the motion ability mainly. The degree of spasticity was also selected to be mild according to the modified Ashworth scale so its effect on gait deviations and post treatment evaluation is minimized. The duration of illness was chosen to be less than 3 months as the improvement in the absolute values of the distance and temporal measures of walking have been observed with increasing time from the onset of the stroke [27,28], with respect to the time from the onset of the infarct, the most rapid improvements have been observed over the first six weeks to three months, with slower changes being evident up to one year [29,30]. Quantitative electroencephalography (QEEG) is a non-invasive technique that allows a highly precise measurement of brain function and connectivity. QEEG features are sensitive to modification in neuronal regulation dysfunction which may therefore help in detecting regions of altered brain function and connectivity abnormalities [31]. In a resting state, (lower frequency) theta band activity can reflect drowsiness or "cortical slowing." Alpha band activity is typically observed during eyes closed at rest, particularly in posterior regions, and it is negatively associated with central nervous system arousal. Beta band activity, by contrast, generally accompanies mental activity and concentration. A thetato-beta power ratio measured at the vertex $(\mathrm{Cz})$ during eyes-open or eyes-closed resting condition has been proposed to capture the relative contributions of two relevant frequency bands for diagnosing and monitoring ADHD [32]; however, the true functional significance of this measure remains unknown. The affected hemisphere showed high theta/ beta ratio in the pre-treatment evaluation which improved in the post treatment one. The subcortical infarct caused ipsilaterally increased slow and decreased fast frequency activity accompanied by decreased synchronization of slow, increased synchronization of fast frequencies. Reduced reactivity in the ischemic side was particularly apparent for complexity measures. The decreased synchronization in the slow frequencies in the infarct side is probably the result of lesioned interneuronal connections lowering the level of cooperation of neuronal systems involved in this type of activity $[33,34]$.

There was significant improvement of all post treatment evaluation tests of gait including the TUG, Cadence, Speed and FMS.

In previous studies; the combination treatment of 20 sessions, 2000 pulses of $10-\mathrm{Hz}$ rTMS delivered over bilateral leg motor areas using the double cone coil with intensive physiotherapy, significantly increased walking velocity and decreased Physiological Cost Index and decreased the performance time for TUG [35]. Fugl-Meyer Assessment and the Wolf Motor Function Test were applied before and after rTMS to evaluate motor function in the affected upper limb. Changes in asymmetry index (AI) in the superior and middle frontal areas correlated significantly and negatively with changes in FMA score [36].

In this study; the gait evaluation tests could not be correlated to the increased power of the fast frequency bands (alpha and beta) in relation to the slow band (theta) in either affected or unaffected hemisphere. The confusion as to the functional association, significance, or "meaning" of EEG measures may result from analyzing the data at the level of individual scalp channels rather than the cortical source level. Channel signals are, in fact, weighted mixtures of source signals originating from many different cortical regions supporting distinct cognitive functions (plus signals from non-brain artifact sources). Thus, any single-channel based measure mixes potentials from several sources, not all of which contribute to the effect of interest, thereby constituting noise in the signal of interest [37].

\section{Conclusion}

Although rTMS for the unaffected hemisphere after stroke improves the gait ability of the patient as well as the fast frequency band of the EEG yet they are not correlated to each other.

\section{References}

1. Janet $\mathrm{H}$ and Roberta $B$ (2003) Stroke rehabilitation guidelines for exercise and training to optimize motor skill.1st ed. 76-128.

2. Chen G, Patten C, Kothari DH, Zaiac FE (2005) Gait differences between individuals with post-stroke hemiparesis and non-disabled controls at matched speeds. Gait Posture 22: 51-56.

3. Lin PY, Yang YR, Cheng SJ, Wang RY (2006) The relation between ankle impairments and gait velocity and symmetry in people with stroke. Arch Phys Med Rehabil 87: 562-568.

4. Cassidy JM, Gillick BT, Carey JR (2014) Priming the brain to capitalize on metaplasticity in stroke rehabilitation. Phys Ther 94: 139-150.

5. Kobayashi M, Hutchinson S, Théoret H, Schlaug G, Pascual-Leone A, et 
Citation: Elkholy SH, Atteya AA, Hassan WA, Sharaf M, Gohary AME (2014) Low Rate Repetitive Transcranial Magnetic Stimulation (rTMS) and Gait Rehabilitation after Stroke. Int J Neurorehabilitation 1: 109. doi:10.4172/2376-0281.10001109

al. (2004) Repetitive transcranial magnetic stimulation of the motor cortex improves ipsilateral sequential simple finger movements. Neurology 62: 91-98.

6. Liepert J, Graef S, Uhde I, Leidner O, Weiller C (2000) Training-induced changes of motor cortex representations in stroke patients. Acta Neurol Scand 101: $321-326$

7. Liepert J, Hamzei F, Weiller C (2000) Motor cortex disinhibition of the unaffected hemisphere after acute stroke. Muscle Nerve 23: 1761-1763.

8. Maeda F, Keenan JP, Tormos JM, Topka H, Pascual-Leone A (2000) Modulation of corticospinal excitability by repetitive transcranial magnetic stimulation. Clin Neurophysiol 111: 800-805.

9. Fregni F, Boggio PS, Valle AC, Rocha RR, Duarte J, et al. (2006) A shamcontrolled trial of a 5-day course of repetitive transcranial magnetic stimulation of the unaffected hemisphere in stroke patients. Stroke 37: 2115-2122.

10. Werhahn KJ, Conforto AB, Kadom N, Hallett M, Cohen LG (2003) Contribution of the ipsilateral motor cortex to recovery after chronic stroke. Ann Neurol 54 464-472.

11. Mansur CG, Fregni F, Boggio PS, Riberto M, Gallucci-Neto J, et al. (2005) A sham stimulation-controlled trial of rTMS of the unaffected hemisphere in stroke patients. Neurology 64: 1802-1804.

12. Kirton A, Chen R, Friefeld S, Gunraj C, Pontigon AM, et al. (2008) Contralesional repetitive transcranial magnetic stimulation for chronic hemiparesis in subcortical pediatric stroke: a randomized trial. Lancet Neural. 7: 507-513.

13. Málly J, Dinya E (2008) Recovery of motor disability and spasticity in poststroke after repetitive transcranial magnetic stimulation (rTMS). Brain Res Bul 76: 388-395.

14. Kim YH, You SH, Ko MH, Park JW, Lee KH, et al. (2006) Repetitive transcranial magnetic stimulation-induced corticomotor excitability and associated motor skill acquisition in chronic stroke. Stroke 37: 1471-1476.

15. Izumi S, Kondo T, Shindo K (2008) Transcranial magnetic stimulation synchronized with maximal movement effort of the hemiplegic hand after stroke: a double-blinded controlled pilot study. J Rehabil Med 40: 49-54.

16. Hankey GJ (2007) Stroke your questions answered. 2nd ed 2007; Churchil Livingstone. pp 188.

17. Folestein MF, Folestein SE, Mc Hugh PR (1975) Mini Mental State: A practica method for grading the cognitive state of patients for the clinician. J Psychia. Res. 12: 189-198.

18. Bohannon RW, Smith MB (1987) Interrater reliability of a modified Ashworth scale of muscle spasticity. Phys Ther 67: 206-207.

19. Bobath B (1990) Adult hemiplegia. Evaluation and treatment. 3rd ed. Oxford: Heinemann Medical, 1990.

20. Brunström S (1970) Movement therapy in hemiplegia: a neurophysiological approach Philadelphia PA, Harper \& Row 78-96.

21. Caroyln K, Lynn A (1990) Therapeutic exercises: Foundations and techniques, 2nd edition, Davis F.A. 109-146, 429-472.

22. Margret $\mathrm{H}$ and Phyi $\mathrm{F}$ (1999) Practical exercise therapy. 4th edition, Wiley 260-
23. Hausdorff JM1, Ladin Z, Wei JY (1995) Footswitch system for measurement of the temporal parameters of gait. J Biomech 28: 347-351.

24. Scott B, Kathryn B, Allan D, Holly Fritz, Bob Goodman et al. (2003) Measurement of balance: comparison of the timed up and go test and functional reach test with berg balance scale. J. Phys. Ther. Sci. 15: 93-97.

25. Fugl-Meyer AR, Jääskö L, Leyman I, Olsson S, Steglind S (1975) The poststroke hemiplegic patient. 1. a method for evaluation of physical performance. Scand J Rehabil Med 7: 13-31.

26. Kerrigan DC, Scaufele M and Wen MN (1998) Gait analysis. In: Rehabilitation medicine principles and practice. DeLisa JA, Gans BM, eds 3rd ed. Philedelphia: lippincott-Ravan, 167-187.

27. Mizrahi J, Susak Z, Heller L, Najenson T (1982) Variation of time-distance parameters of the stride as related to clinical gait improvement in hemiplegics. Scand J Rehabil Med 14: 133-140.

28. Brandstater ME, de Bruin H, Gowland C, Clark BM (1983) Hemiplegic gait: analysis of temporal variables. Arch Phys Med Rehabil 64: 583-587.

29. von Schroeder HP, Coutts RD, Lyden PD, Billings E Jr, Nickel VL (1995) Gait parameters following stroke: a practical assessment. J Rehabil Res Dev 32 25-31

30. Jørgensen HS, Nakayama H, Raaschou HO, Vive-Larsen J, Støier M, et al. (1995) Outcome and time course of recovery in stroke. Part II: Time course of recovery. The Copenhagen Stroke Study. Arch Phys Med Rehabil 76: 406-412.

31. Billeci L, Sicca F, Maharatna K, Apicella F, Narzisi A, et al. (2013) On the application of quantitative EEG for characterizing autistic brain: a systematic review. Front Hum Neurosci 7: 442

32. Monastra VJ, Lubar JF, Linden M, Van Deusen P, Green G, et al. (1999) Assessing attention deficit hyperactivity disorder via quantitative electroencephalography: an initial validation study. Neuropsychology 13: 424433.

33. Molnár M, Csuhaj R, Horváth S, Vastagh I, Gaál ZA, et al. (2006) Spectral and complexity features of the EEG changed by visual input in a case of subcortical stroke compared to healthy controls. Clin Neurophysiol 117: 771-780.

34. Molnár M, Csuhaj R, Horváth S, Vastagh I, Gaál ZA, et al. (2006) [Changes in EEG-complexity after subcortical ischemic brain damage]. Ideggyogy Sz 59: 185-192.

35. Kakuda W, Abo M, Watanabe S, Momosaki R, Hashimoto G, et al. (2013) Highfrequency rTMS applied over bilateral leg motor areas combined with mobility training for gait disturbance after stroke: a preliminary study. Brain Inj 27: 10801086.

36. Takekawa T, Kakuda W, Uchiyama M, Ikegaya M, Abo M et al. (2013) Brain perfusion and upper limb motor function: A pilot study on the correlation between evolution of asymmetry in cerebral blood flow and improvement in Fugl-Meyer Assessment score after rTMS in chronic post-stroke patients. $J$ Neuroradiol [Epub ahead of print]

37. Loo SK, Makeig S (2012) Clinical utility of EEG in attention-deficit/hyperactivity disorder: a research update. Neurotherapeutics 9: 569-587. 